Cilt-Volume: 2 | Sayl-Issue: 1 | Sayfa-Page: 23-33 | Bahar-Spring | Yıl-Year: 2017

IBAD, 2017; 2(1): 23-33 Geliş tarihi/First received: 29.12.2016 Kabul tarihi/Accepted: 01.20.2017

\author{
NAHÇIVAN BÖLGESİ ERKEN TUNÇ ÇAĞI SERAMIKK \\ DESENLERININ YAYILIM ALANI VE ANLAMI HAKKINDA*
}

Özet

\author{
Doç. Dr. Toğrul HALÍLOV ${ }^{1}$
}

\begin{abstract}
Makalede Nahçıvan'ın Erken Tunç Çağı yapılarından bulunan seramiklerin üzerindeki desenlerin anlamı ve yayılma alanı araştırılmıştır. Yapılan araştırma sırasında Erken Tunç Çağı'nda Nahçıvan'da seramik sanatının uzmanlaşmış üretim alanına dönüştüğü görülmektedir. Bu sanat alanının gelişmesi nedeniyle seramik ürünlerinin yapılmasında, firınlanmasında değişikler olmuştur. Erken Tunç Çăgı'na ait kapların bezemesinde oval veya yuvarlak motifler, zikzak, svastika, "S", "M" vb. desenler kulanılmıştır. Çeşitli desenlerin kulanılması seramikçilerin üretim alışkanlıkları ile birlikte dini-ideolojik görüşleri ile de bağlantılıdır. Desenler basit ve bileşik konuludur. Desenlerin hem yerel özellik taşıdığı, hem de diğer kültürlerle benzerlik oluşturduğu görülür. Süslemede yerel desenlerin yanı sıra, diğer kültürlerle benzer özelliklerin bulunması farklı bölge insanların dini-ideoloji görüşlerinin benzer olduğunu, her bir desenin derin bir anlamı olduğunu kanıtlamaktadır.
\end{abstract}

Anahtar kelimeler: Çömlekçilik, Erken Tunç Çağı, Desen, Nahçıvan, Yayılma Alanı

\title{
ABOUT THE SEMANTICATION AND SPREADING AREA OF A GROUP ORNAMENTS ON CERAMICS OF THE EARLY BRONZE AGE OF NAHCHIVAN REGION
}

\begin{abstract}
The pattern of the ornaments (patterns) on ceramic products found in Nakhchivan's Early Bronze Age constructions has been researched. During the research conducted during the Early Bronze Age, Nakhchivan stated that the art of ceramics became a specialized production area. Due to the development of this art field, there have been changes in the way ceramic products are made and cooked. During the exposition of the vessels belonging to the Early Bronze Age or round wattles, zigzags, swastik, S, M and s. shaped signs, horns, spiral ornaments, various geometric patterns are used. Each of the patterns is a commitment to ceramists' workmanship habits and religious-ideological views. The patterns are simple and compound. They have both local characteristics and similarities with other cultures. In addition to local ornamentals, the presence of similar ornaments in other cultures proves that the people of the different regions of the world are alike in their religiousideological views, and that each ornament has its deepest semantics.
\end{abstract}

Keywords: Pottery, Early Bronze Age, ornament, Nakhchivan, Spread

\footnotetext{
*Bu çalışma Azerbaycan Cumhuriyyeti Cumhurbaşkanı himayesindeki Bilimin gelişmesi fondunun maili yardımı ile gerçekleştirilmiştir-Grant №EIF-KETPL -2-2015-1(25)-56/47/5

Özgün Araştırma/Original Article

1 Sorumlu yazar/Corresponding Author: Azerbaycan Milli Bilimler Akademisi Nahçıan Bölümü, Azerbaycan, x.toqrul@gmail.com
} 


\section{Giriş}

Erken Tunç Çağı'nda Kafkaslardan Fırat Nehri'ne kadar uzanan coğrafyada farklı isimlerle anılan bir kültürün etkisi görülmektedir. Bu kültüre yönelik isimlendirme Galilee'de ki (İsrail) Khirbet Kerak Höyügü'ne dayandırılarak "Khirbet Kerak / Beth Yerah" olarak yapılmıştır. (Sukenik 1922: 101-108; Albright 1926: 27-31) Diğer isimlendirmeler ise Karaz Höyük’e (Erzurum) dayandırılarak "Karaz Kültürü”, Trialeti kazılarına dayandırılarak "KurAras Kültürü", Amik Ovası seramiklerine dayandırılarak "Kırmızı-Siyah Açkılı Seramik Kültürü” (Red and Black Burnished Ware), Yanıktepe Kazılarına (Urmiye Gölü) dayandırılarak "Yanık Kültürü", Korucutepe Kazılarına (Elazığ) dayandırılarak "Verimli Hilal Dışındaki Kültür" olarak isimlendirmiştir. (Koşay 1943: 165-169; Koşay-Turfan 1959: 359; Kuftin 1943: 92-123; Braidwood -Braidwood 1960; Dyson 1968: 14-16; Dyson, 1973: 686-714; KellyBucellati 1974: 5; Kelly-Bucellati 1979: 413) Ayrıca Burney tarafindan 1950'li yıllarda "Eski Transkafkasya Kültürü ve Doğu Anadolu'nun Erken Bronz Çağı” (Early Trans-Caucasian Culture and Eastern Anatolia Early Bronze Age) daha sonra ise "Erken Transkafkasya Kültürü" (Early Trans-Caucasian Culture), Piotrovskii ile Krupnov tarafindan "Transkafkasya'nın Eneolitik Kültürü" şeklinde bir tanımlamada yapılmıştır. (Burney 1958: 165, 173; Piotrovskii 1964: 360-361; Burney- Lang 1971: 43-44; Topaloğlu 2008: 355; Topaloğlu 2009: 248)

Tüm bu farklı isimlendirmelere rağmen kültür Azerbaycan arkeolojisinde "Kür-Aras Kültürü” olarak isimlendirilmiştir.

$\mathrm{Bu}$ kültüre ait arkeolojik anıtlar bu geniş coğrafyada olduğu gibi Azerbaycan'ın tüm bölgelerinde ve Nahçıvan'da da vardır. I Kültepe, II Kültepe, Ovçulartepesi, Maxta Kültepesi, Halaç, Erebyengice, Şortepe vb. böyle yerleşimlerdir. Bu arkeoloji yerleşim buluntuları Erken Tunç Çağı insanlarının yaşam tarzını, işçilik alanlarını, toplumlar arası ekonomik-kültürel ilişkileri ve diğer konuları öğrenmek olasıdır. Nahçıvan bölgesindeki Erken Tunç Çağı'na ait yerleşimlerden bulunan seramik malzemeler önemli bir yer tutmaktadır. $\mathrm{Bu}$ seramik malzemelerin büyük bir kısmını kil ocaklar, mangallar, kap altlıları ile tekerlek ve hayvan figürleri oluşturmaktadır. Her bir arkeolojik buluntu kendi içerisinde farklı özelliklere sahip olduğu görülmektedir.

Erken Tunç Çağı'na ait kil ocaklar nal biçimli ve dikdörtgen yapılmıştır. Onların bir grubu basittir. Bazılarının arka kısmında yarımşar biçimli kulp yapılmıştır. Mangallar dairesel, kap altılıkları silindirik, yuvarlak ve dikdörtgen biçimdedir. Tekerlek modelleri dairesel, biçimde yapılmıştır, onun orta kısmında bir delik açılmıştır. Kil hayvan figürleri öküz, at, köpek figürlerinden oluşmaktadır (Seidov, 2002: 67, 72, 75). I Kültepe Höyüğü’nün Erken Tunç Çağ1 tabakasında, Mahta'dan, Ovçulartepesi'nden bu türlü arkeolojik bulgular bulunmuştur. I Kültepe'den 21 (Abibullayev , 1982: 141), Mahta'dan 4 (Aşurov, 2002: 65) adet hayvan figürü bulunmuştur. Onların çoğu boğa figürleridir. Bu figürlerden her birinin spesifik özelliği vardır. I Kültepe yerleşiminde bulunmuş boğa figürlerinden bir kaçının burnunda oyuk çılmıştır. Bazılarının gözleri ise çizme yöntemi ile yapılmıştır. Bu özellikler Mahta yerleşiminin boğa figürlerinde de görülür. I Kültepe yerleşiminin Erken Tunç Çağı tabakasında bulunmuş boğa figürlerinden birinin boynuzları yukarı kalkmış durumda yapılmıştır. Figürün kuyruğu arkaya çıkıntılı biçimde, gözleri küçük oyukla verilmiştir (tab. I, 2).

Kültepe I yerleşiminde bulunmuş bacakları bir-birinden uzakta yapılmış boğa figürlerinden bir kısmının başı uzun biçimde yapılmıştır (tab. I, 3). Bazı boğa figürlerinin gövdesi arkadan enine doğru genişlemiş, başı ise çıkıntı ile ifade edilmiştir (tab. I, 7). Bir grubunun bacakları bitişik yapılmıştır (tab. I, 4). 
Mahta yerleşiminden bulunmuş boğa figürlerinden biri kafası ileriye doğru yönelmiş, boynuzları hilal biçimde, bacakları ise hareket durumunda yapılmıştır. Onlar arasındaki benzerlik figürlerin çoğunluğunun ayaklarının, bir grubunun ise boynuzlarının kırılmasıdır.

Mahta yerleşiminden bulunmuş boğa figürlerinden biri Anadolu'da bulunmuş eski (http://www.gezi.gen. tr/destinasyonlar_bogazkale.asp) bir grup boğa figürleri ile pek benzerlik göstermektedir. Onun boynuzları hilal biçimde, bacakları ise hareket durumunda yapılmıştır. Boyun kısmında ikili oyuk açılmıştır (tab. I, 26). Bu figürün sol yanı üzerinde kavis biçiminde yapılan noktasal dört küçük oyuk, Göytepe yerleşiminden bulunmuş bazı bogaboğa figürlerinde de bulunmaktadır. Dikey yönde dizilen görünüşçe hilal tasvirine benzer noktaların sayı ve yapım yönünden Göytepe figürlerinden çok az farklılık taşımaktadır.

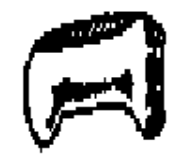

1

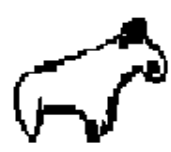

7

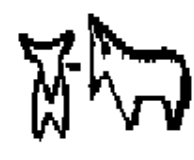

2

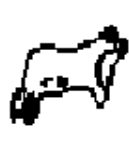

8

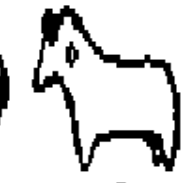

3

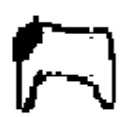

9

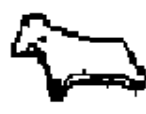

10

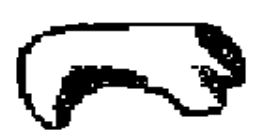

4

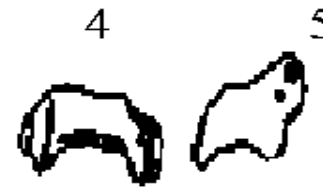

11
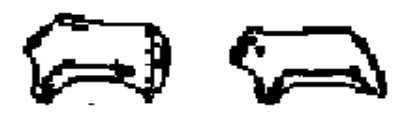

6

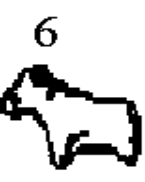

14

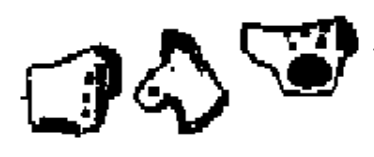

15

16

17

18
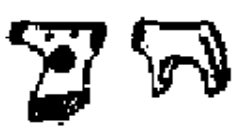

19

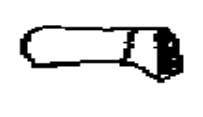

20

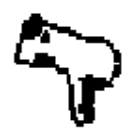

21

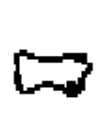

22

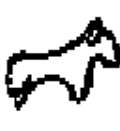

23

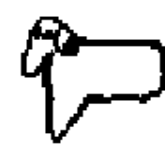

24

(Abibullayev, 1982)

Tablo I. Kil hayvan figürleri

Kil hayvan figürlerinin kullanım amacı ve yapılış anlamı ile ilgili birçok düşünce vardır. Araştırmacı Osman Hebubullayev'in düşüncesine göre figürlerin kırılmasının nedeni onlardan dini ritüellerde kullanılmasıdır. Bir grup tip boğa figürleri küçük araba modellerine bağlanmak için yapılmıştır (Abibullayev, 1982: 143). S. Aşurov'a göre bu tip boğa figürlerinden amulet olarak, verimlilikle dini ayinlerde kullanılmıştır. Bu nedenle Mahta yerleşiminde bulunmuş bu tür kil hayvan figürlerinin ensesindeki deliğin kenarında değil, içerisinde sürtünme izleri Aşurov, 2002: 67).

Kil hayvan figürlerinin kullanım amacı, ve yapılış anlamı ile ilgili araştırmacıların düşünceleri farklı olsa da, onları lojistik yönden, mantıksal açıdan birleştiren önemli konu figürlerden gibi kullanılmasıdır. Yani büyük bir ihtimalle tüm hayvan figürlerinin yapılmasının temel nedeni bu hayvanların insanların ekonomik hayatında geniş yer tutması nedeniyle bu çağda (Erken Tunç Çağı) insanlarının dini-ideolojik görüşlerinde hayvan kültü önemli yer tutmuş, bu figürler hayvan kültünü yansıtmıştır.

Nahçıvan'ın Erken Tunç Çağı yerleşimlerinden (I Kültepe, II Kültepe, Ovçulartepesi, Mahta, Erebyengice, Şortepe vb.) bulunan seramikler sırasında kil kaplar çok sayıdadır. Bunun nedeni insanların hayatında kil kapların daha çok yer tutması ve yoğun olarak kullanılmasıdır. Bu kaplar sofra ve çiftlik (depo) kapları olmak üzere iki gruba ayrılır. Sofra kaplarının kilinin bünyesine narin, çiftlik kaplarının bünyesine iri kum taneleri katılmıştır. Onlar gri, siyah ve 
pembe renkte yapılmıştır. Birçoğu cilasızdır. Siyah renkli seramiklerin bir grubunu balon gövdeli, düz ayaklı, silindirik boğazlı, yarımşar veya boğa burnu biçimli kulplu kablarkaplar oluşturur. Bu tip kulplar Erken Tunç Çağı'nın spesifik özelliklerindendir. Nahçıvan'ın Erken Tunç Çağı yapılarının bir grubundan ilmi literatürde "manda derisi renkli" seramik adıyla bilinen kahverengi kil kaplar da bulunmuştur. Plovdağdan ve diğer yerleşimlerden bulunmuş bu türlü seramiklerin benzerlerinin Giyan, Mussiana ve Suzda yaygın olduğu belirtilmiştir (İbrahimli, Qedirzade, Xelilov vb. 2011: 167).

Nahçıvan'ın Erken Tunç Çă̆ı seramikleri form ve kil renginin yanı sıra bezeme yöntemi ve desenlerinin tipolojisiyle de ilgi çekicidir. Kapların süslenmesinde oval veya yuvarlak motifler, zikzak, svastika, S, M ve s. biçimli işaretler, boynuz, spiral ve çeşitli geometrik, tarak biçimli desenler, kabarık uzantılar vb. kullanılmıştır. Desenler çizme oyma, basma, kabartma teknik yöntemleri ile yapılmıştır. Bu desenlerden her biri seramikçilik sanat alanı ile uğraşan insanların (seramikçinin) işçilik alışkanlıkları, sanatkârlığının yanı sıra diniideolojik görüşleri ile bağl1lık oluşturur. Desenler basit ve bileşik konuludur. Onlar hem yerel özellik taşımakta hem de diğer kültürlerle benzerlik göstermektedir. Düşüncelerimizi kanıtlamak için arkeolojik kaynaklara baktığımızda üzeri oval veya yuvarlak desenlerle süslenmiş kil kapların Nahçıvan ile birlikte dünyanın birçok bölgesinde görülmektedir. (KoşayTurfan 1959: 359, 395-396; Burney-Lang 1971: 57; Sukenik 1974: 9-14; Pehlivan 1990: 168176; Çiğdem 2000: 201-202; Ceylan 2008: 82; Ünsal 2008: 400; Işıklı 2011: 67-78; Topaloğlu 2016: 1202). Nahçıvan'da bu tip kaplar I Kültepe, II Kültepe, I Mahta, Güney Azerbaycan'da Göytepe yerleşiminde bulunmuştur (Bahşeliyev, 2004: 50; Eliyev, Aşurov, 1992: 33-36). I Kültepe yerleşiminde kil kapların yanı sıra VII, XI. yapı katından seramik firınının buluntuları da tespit olunmuştur (Seidov, 1993: 120). I Maxta yerleşim yerinden elde edilen kapların birçoğunun üzeri Nahçıvan'ın diğer Erken Tunç Çağı yapılarından bulunan seramikler gibi c1zma çizgi desenlerle süslenmiştir (Seidov, 2003: şekil 27). I Kültepe yerleşiminde bulunmuş üzeri kabartma teknikle işlenmiş " $M$ " biçimli kil kaplar (Abibullayev, 1982: 133) Yanıktepe yerleşiminde elde edilmiş bir grup kaplarla benzerlik oluşturmaktadır (Kuşnaryeva, Çubinaşvili, 1970: 89). Azerbaycan'da Babaderviş, Doğu Gürcistan'da Amiranisqora, Anakliya yapılarından bu tip desenli kil kaplar bulunmuştur (Kuşnaryeva, Markovin, 1994: 26, 68). I Kültepe (Abibullayev, 1982: 127), II Kültepe (Aliyev, 1991: 123) yerleşimlerinde tespit olunan üzeri zikzak dersenli kil kaplar Güney Kafkasya'nın (Kuşnaryeva, Çubinaşvili, 1970: s. 166), Ön Asya'nın (Sevin, Özfırat, Kavakl1, 20008: 852; Sagona-Sagona 2003:101-109; Öztürk 2004: 8193; Pehlivan 1990: 168-176; Ünsal 2006:127-142) aynı çağa ait olan arkeolojik yerleşimlerinden bulunmuş bir grup kaplarla benzerlik oluşturmaktadır. "S" desenli seramiklerin benzerleri Nahçıvan'ın yanı sıra Yanıktepe (Kuşnaryeva, Çubinaşvili, 1970: 125), Amiranisqora yapılarından bulunmuştur (Kuşnaryeva, Markovin, 1994: 28) (tablo 2, 3, 4, 5). Spiral, svastika, boynuz desenlerinin benzerleri dünyanın çeşitli bölgelerinden bulunan kaya üstü simgelerde, seramik ürünlerinin üzerinde tespit edilmiştir. "S" biçimli desenin sembol veya damga gibi kullanılması ile ilgili net fikir söylemek biraz zordur. Ancak şunu belirtmek gerekir ki, her bir süsleme kompozisyonu, desenleme seramiklerin üzerine hiçbir zaman tesadüfen çekilmez, onlar hem seramik ustasının yeteneğini yansıtır, hem de insanların düşünce tarzını, dini-ideolojik görüşleri ile bağlllık oluşturur . Bu nedenle, bazı desenler sadece lokal karakter taşımadığı, geniş bir yayılma alanı olduğu görülür. Dünyanın çeşitli topraklarına yayılan bu desenler sembol ve ya damga gibi kullanılmıştır. Bunun temel nedenlerinden birini ise, dünyanın farklı coğrafyalarında yaşayan insanların ilkel dini-ideolojik görüşünde, mitolojik düşünce tarzının etkili olması oluşturmaktadır.

Fikrimizi kanıtlamak için kaynaklara baktığımızda görürüz ki, "S" biçimli desenlerin eski örnekleri Tripolye Tunç (Eneolit) Kültürü'ne ait (M.Ö. VII -VI binyıllar) kil kapların üzerinde tespit edilmiştir. İskitlerin Saka (Apasiak) aşiretlerinin metal malzemeleri (M.Ö. VI-IV 
yüzyıllar), Özbekistan'ın Karakalpak toprağındaki Anşka-Kalı denilen bölgede bulunan metal deve figürü üzerinde (M.Ö. I yy-I yy), Sırderya Nehri kıyılarındaki Çirik-Rebat Kültürüne ait seramik kaplarda, Harezm sikkelerinde (II yüzyıl), Güney Türkmenistan'ın mimarlık elementlerinde (X-XI yüzyıllar) bu tür desenler bulunmaktadır (Allamuratov, 1977: 45). Bu desenlerin anlamı konusunda yapılan araştırmalar sırasında belli oluyor ki, "S" deseninin geniş yayılma alanı, ve çeşitli sembolik anlamı bulunmaktadır. Azerbaycan'da "karmak", Anadolu'da ise "çengel" denilen bu desen hem. Azerbaycan halı desenlerinde hem de "akarsu" adıyla kalmaktadır. Azerbaycan ve Anadolu halı sembolizminde insanı tehlikeden, kötü gözden kurtarmak için kullanılan motiftir. (Qurbanov, 2003: 260). Orta Asya'da damga işareti gibi çeşitli isimleri vardır. Kazaklar bu işarete "bota moyın" (köşek boynu), "gaz moyın" (gaz boynu), Kırgızlar "it quyruqşa" (itkuyruğu), Özbek ve Karakalpaklar "qumırska beli" (karınca beli) demektedir. Çuvaşlar ise onu sema nurunun, güneş ışığının sembolü olduğunu düşünürler. "S" deseni Kazaklarda damga kimi kulanılmıştır (http://www.sanat.orexca.com/rus/archive/209/irina_bogoslovskaya.shtml). Kaşğarlı Mahmud'un "Divan-Lugat-it Türk" eserinde de bu desen hakkında bilgiler bulunmaktadır. Orada bu tip işaretin Oğuzların Beydili aşiretinin damgası olduğu belirtilmiştir (Kaşğarl1, 2011: 227). "Şecereyi-Terakkime" eserinde bu işaretin yatay seçeneği Oğuzların Iğdır ve Kınık boylarına ait edilmiştir (Ebulqazi, 2002, 100).

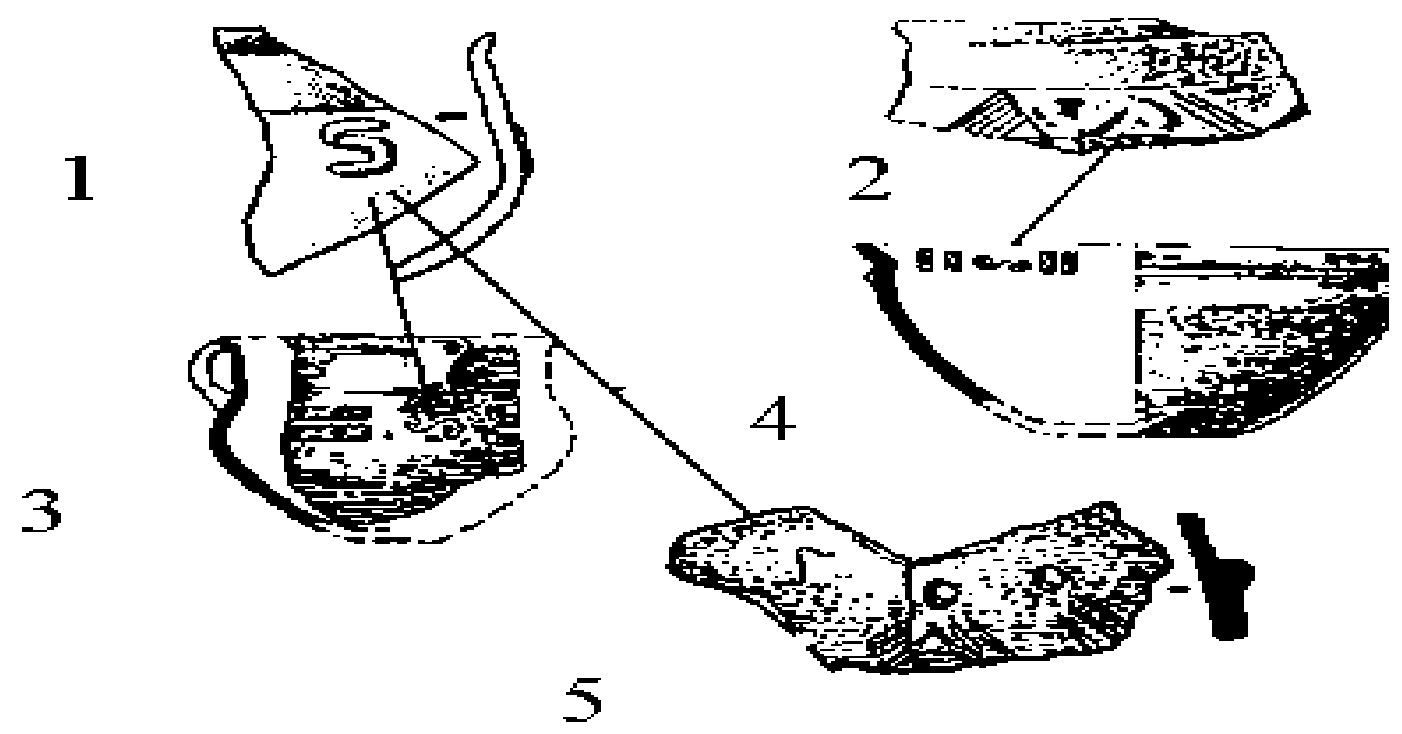

(1,2-II Kültepe (Seidov, 2002; 3, 4- Yanıktepe (Kuşnaryeva, Çubinaşvili, 1970); 5-Amiranisqora (Doğu Gürcistan) (Kuşnaryeva, Markovin, 1994))

Tablo II. "S" desenli seramiklerden örnekler

Tarakvari ve ya "M" biçimli desenlerin anlamı ve yayılma alanı konusunda yapılan araştırmalar sırasında " $S$ " deseninin gibi onun da Azerbaycan halıları üzerinde yoğun olarak kullanılan desenlerden olduğu görülür. Bu desen Azerbaycan'ın yanı sıra Anadolu, Kuzey Kafkasya, Türkmenistan halıcılık sanatında kaplama unsuru olarak yapılmaktadır. Üzeri bu türlü süslü seramikler I Kültepe (Abibullayev , 1982: 291, tab. XI, 10; 302, tab. XXII, 9), Babaderviş, Amiransqora (Kuşnaryeva, Markovin, 1994: 29, 68) vb. yerleşimlerde (tablo. III, 1, 2, 3). Damgalar sirasinda "yüksek hakimiyet ve vassallar", "vassallık" bildiren Han damgas1, baltavar, ilteber / elteber sembolleri ile benzerlik oluşturmaktadır (Qurbanov, 2003: 49). Talas, Orhun ve Yenisey kullanılan "g" ünsüzünü bildiren işaretler de bu şekildedir. (Tekin, 2010: 150), "Şecereyi-Terakkime" eserinde ise bu tip işaretler Oğuzların Döger boyunun damgası olarak gösterilmiştir. (Ebulqazi, 2002: 77) . 


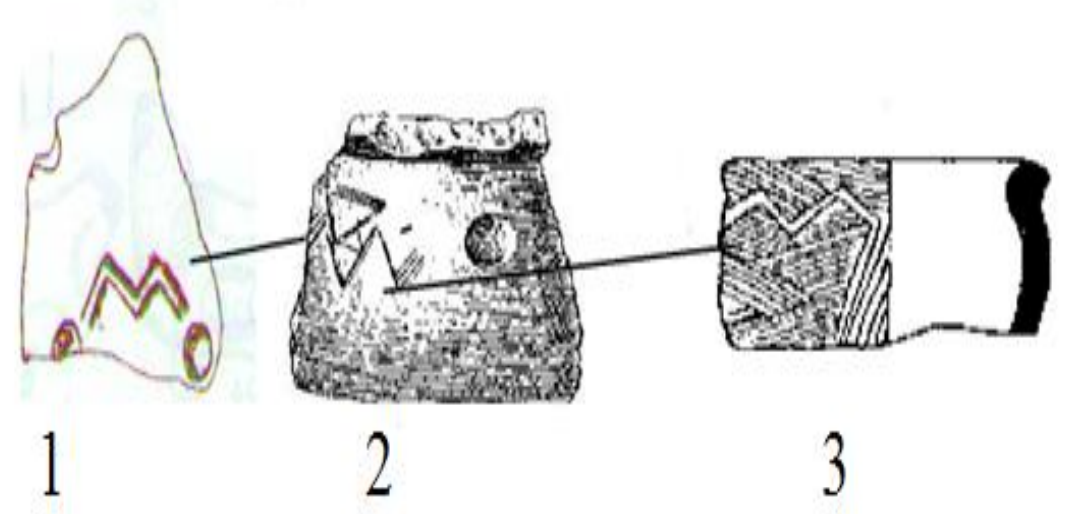

\section{(1-I Kültepe (Abibullayev, 1982); 2- Babaderviş;3-Amiranisqora (Doğu Gürcistan) (Kuşnaryeva, Markovin, 1994))}

\section{Tablo III. Tarakvari ve "M" desenli seramiklerden örnekler}

Nahçıvan'ın Erken Tunç Çağı seramikleri üzerinde bulunan desenlerden koç boynuzu biçiminde olanlar özel bir yer tutmaktadır. Yapılan araştırmalar sırasında Nahçıvan'ın yanı sıra bu tip süslü seramiklerin Azerbaycan'ın diğer topraklarında ve Doğu Gürcistan'da da (Kuşnaryeva, Markovin, 1994: 19) yaygın olduğunu görürüz (tablo IV, 1-7) . Bu desenin anlamı ve yayılma alanı ile ilgili yapılan araştırmalar sırasında koç boynuzunun, koçun eski Türk mitoloji düşüncelerinde tıbbi sembollerden olduğunu görürüz. Koç bir yandan "bolluk" ve "bereket" anlamına gelir, diğer yandan ise ölen insanların ruhlarını Tanrı mekanına ulaştıran kutsal canlılardan düşünülüyordu. Bu nedenle Tanrıya kesilen kurbanlar arasında beyaz atla birlikte beyaz koç da özel bir yer tutar. Bu desenin en eski örnekleri Tripolye Tunç (Eneolit) Kültürü’ne (M.Ö. VII -VI binyıllar) ait kil kapların üzerinde görülmektedir. Koçboynuzu deseni seramik mamullerin yanı sıra metal mamullerde, halıcılıkta, kayaüstü resimlerde yaygındır. Azerbaycan'la birlikte Anadolu, Türkmen, Karakalpak, ayrıca Dağıstan, özellikle Tabasaran halılarında boynuz deseninin çeşitli biçimleri bulunmaktadır. Azerbaycan halı sanatında Karabă̆ (Malıbeyli) halılarında bu desen dahak yaygındır. Koç boynuzunun anlamı ile ilgili çeşitli düşünceler vardır. Kaynaklarda koç "qoçkar, köçkar, kaçkar" gibi farklı isimlerde kullanılmıştır. Damga işareti gibi Anadolu'da, Güney ve Kuzey Kafkasya'da, Orta Asya'da, Kırım'da, Volga boyunda, Doğu Sibirya'da "koşkar", "koçkar", "köçkar", "koç müyüz" (koç boynuzu), "koçkarok", "kayabaran" (kaya baranı / koçu) vb., Altaylarda "kulya" (koç boynuzu) şeklinde kullanılmıştır. Kuzey Kafkasya'da yaşayan Karaçayların "kosxar" (qoçqar, qoşqar), tulpar, semen aşiretlerinin damgası, Kazakların Nayman, Karakirey aşiretlerine ait tanınmafarklılaşma işareti, Hun damgalarından bir grubu boynuz biçimdedir (Qurbanov, 2003: 259, 305, 307). Orhun Yenisey taş kitabelerindeki damgalar sırasında da bu tip işaretler bulunmaktadır (Tekin, 2010: 110). Karakoyunlu ve Akkoyunlu devletlerinin bayraklarında koç resmi çekilmiştir. 

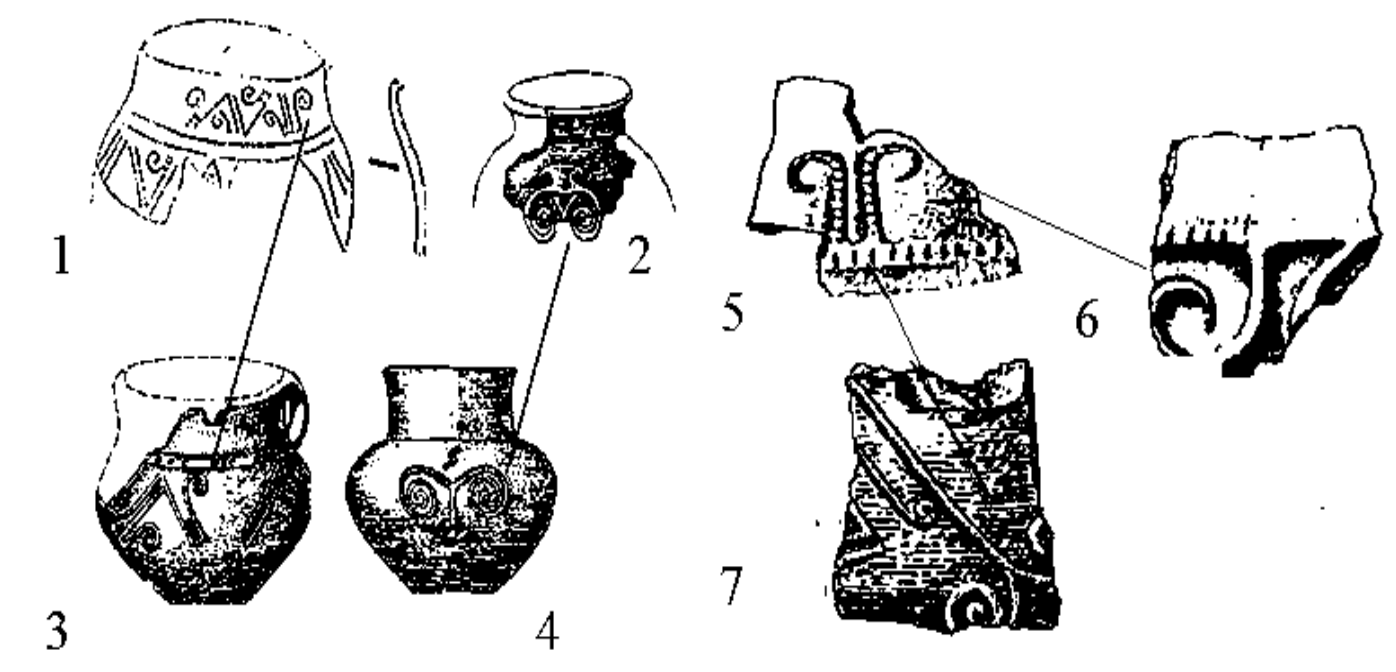

1-Mahta (Seidov, 2003); 2 - I Kültepe (Abibullayev, 1982); 3-Babaderviş; 4- Anakliya (Doğu Gürcistan (Kuşnaryeva, Markovin, 1994); 5, 6- II Kültepe (Seidov, 1993)

\section{Tablo IV. Boynuz Desenli Seramiklerden Örnekler}

Nahçıvan'ın Erken Tunç Çağı yerleşimlerinden bulunan seramiklerin üzerinde tespit olunan desenlerden svastika tasviri de ilgi çekicidir. Bu desenin anlamı ve yayılma alanı konusunda yapılan araştırmalar sırasında onlardan Eski Mezopotamya kültürlerine ait metal paraların üzerinde yoğun olarak kullanıldığı görülmektedir. Dünyada en eski svastika tasviri Ukrayna'da fildişinden yapılmış küçük bir heykelciğin üzerinde tespit edilmiştir. Bu heykelciğin M.Ö. XII. yüzyıla ait olduğu denir (http://onedio.com/haber/nazilerin-kirlettigi-bir-mutluluksembolu-svastika--417203). Ukrayna'nın yanı sıra bu desenin en eski örneklerinin Ön Türklere ait Orta Asya'daki "Karatay" kültürüne ait Karatay, Altay ve Cungar Altayları yapılarında tespit edildiği hakkında bilgiler de kaynaklarda yer almaktadır. Kaynaklarda bu desenin " Karatay" kültüründe yaygın olduğu ve oradan dünyanın başka yerlerine yayıldığı hakkında bilgiler bulunmaktadır (https://uqusturk.wordpress.com/2011/08 / 22 / orta-asyadan-anadoluya-anadoluavrupaya-oz-damgasi). Azerbaycan'da Nahçıvan'ın I Kültepe yerleşiminin yanı sıra Kazak bölgesinde Baba Derviş yerleşiminde bulunan Son Tunç-Erken Demir Çağı'na ait kil mühürlerinin üzerindede bu desen görülür. (Eliyev, 1976: tab. IV, 1), Ayrıca Şemkir'de (Yengi, Bextiyar Tuncay, 2013: s. 31), Hanlardakı (Ferecova, 2009: 76) Tunç ve Erken Demir Çağı kil kaplarında, Gemkaya'da (Müseyibli, 2004, s. 200, daş No.179 a, 6; s. 229, daş No. 294), Gobustan'da (Ferecova, 2009: 40) ve, Kirgizistan'da da (https://onturk.org/tag/saymalitas/) kayaüstü tasvirlerinde svastika tasviri bulunmaktadır. Svastika deseninin tarihi, anlamı gibi onun yayılma alanı hakkında da kaynaklarda çok sayıda bilgiler bulunur. Kaynaklara göz atarsak bu desenin dünyanın çeşitli topraklarındaki birçok kültür ve uygarlıklarda, özellikle de Türk dünyasında sembol ve damga gibi kullanıldığını görürüz. Konya Sırçalı Medrese'de ve Sivas'ta 200 yıllık mezar taşlarının üzerinde tespit edilen Svastika'nın Anadolu kültüründe yaygın olduğunu kullanıldığını kanıtlamaktadır. Bu arkeolojik bulgular Anadolu Medeniyetleri Müzesi'nde sergilenmektedir. (https: //uqusturk.wordpress.com/2011/08/22/orta-asyadananadoluya-anadoludan-avrupaya-oz damgasi) . Geniş bir yayılma alanına ve derin anlama sahip svastika deseni, desenler gibi hem sembol, hem de, damga gibi kullanılmıştır(tablo V). 


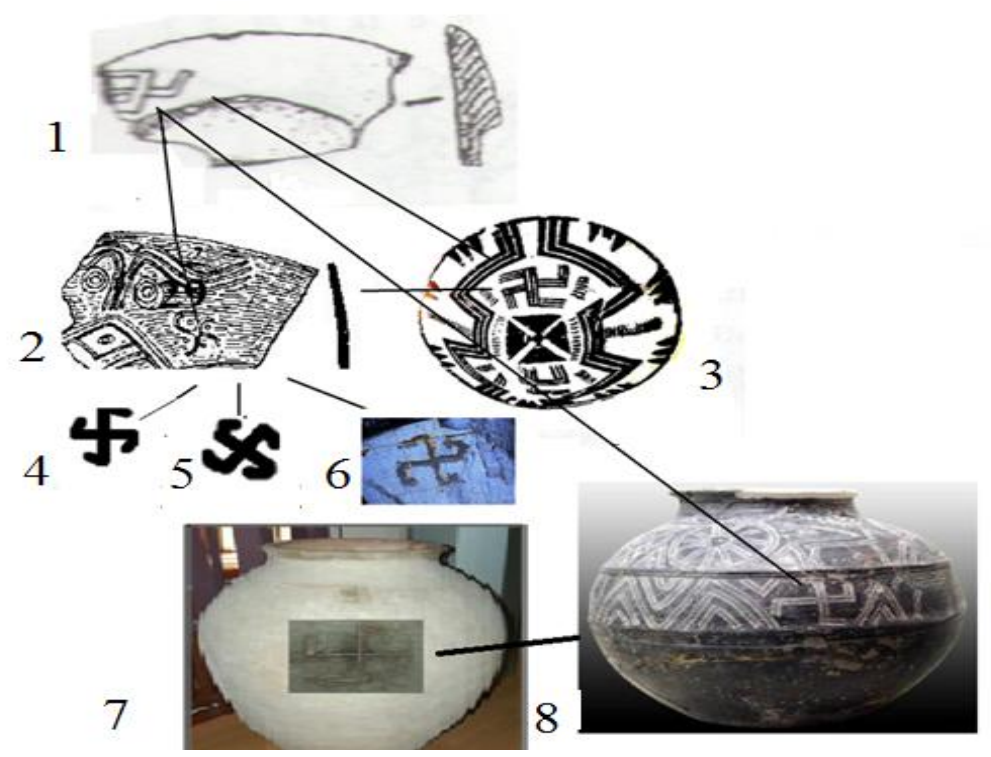

1- I Kültepe (Abibullayev, 1982); 2- Karaz (Doğu Anadolu-Erzurum) (Koşay 1943:165169; Koşay-Turfan 1959; Kuşnaryeva, Markovin, 1994), 3-Iran yaylası (http://azerbaijanistudies.blogspot.com/2013/01/yazmzn-baslangc-gmiqayadak-turk_17.html); 4-Gemiqaya Müseyibli, 2004); 5-Qobustan (Ferecova, 2009); 6-Saymall taş (Kirglzistan) (https://onturk.org/tag/saymalitas/) ; 7-Orta Asiya (https://uqusturk.wordpress.com); 8-Şemkir Rayonu (Yengi, Bextiyar Tuncay, 2013)

\section{Tablo V. Svastika resminden örnekler}

Nahçıvan'ın Erken Tunç Çağı yerleşimlerinde bulunan seramiklerin üzerinde tespit olunan desenlerden spiral tasvirlerde yaygındır. Nahçıvan'ın Erken Tunç Çağı seramiklerinde tek ve birbirine bitişik biçimde görülen spiral tasvirlerde yaygındır. Diğer desenler gibi spiral tasvirlerinde geniş bir yayılma alanı ve derin anlamı vardır. Kaynaklara göz atarsak görürüz ki, bu türlü tasvirler Güney Kafkasya ve Kür-Araz ovasında daha yaygın olduğu görülür (Krupnov, 1964: 39). Nahçıvan'da I Kültepe, II Kültepe, Mahta vb. seramiklerinde bulunmuştur. Bu türlü seramikler Nahçıvan'ın yanı sıra Babaderviş’te, Karaz'da (Koşay 1943:165-169; Koşay-Turfan 1959; Kuşnaryeva, Markovin, 1994: 26) ve dünyanın diğer topraklarında aynı çağa ait tarihlendirilmektedir. (tablo. VI). Dünyada en eski eski spiral tasviri ise İrlanda'da Nevgrange, megalitik yapılarında bulunmuştur. M.Ö. 3200 ile ait olan bu tasvirin doğanın ve evrenin sonsuz gücünü, merkezden başlayan ve dişa doğru gelişen doğa bilincini, birlik ve yükselişi, yaşam deneyimleri aracılığıyla gerçekleşen hareketi temsil eden dolambaç (evrenin sembolü) sembollerden biri olduğu hakkında çeşitli görüşler vardır. (http://www.astroset.com/bireyselgelisim/metabilim/mtblm1.htm). Spiral tasvirli arkeolojik malzemeler Ukrayna Dnepr-Azov bölgesindeki kurganlarda da tespit edilmiştir (Arxeoloqiya Ukraynskoy SSR, 1985: 414). Bu tasvirin anlamıyla ilgili çeşitli bilimsel fikirlerin olduğunu görülür. S.H. Aşurov bu sembolün koçun sembolik işareti olduğunu, onun hayvancilıkla ilgili bazı mitolojik içerik taşıdığını düşünür (Aşurov, 2002: 37). K.X. Kuşnaryeva ve T.H. Çubinişvili'ye göre; spiral sembolünün devamlı hareketin sembolü sayılır ve güneşi temsil ediyor (Kuşnaryeva, Çubinaşvili, 1970: 65-166). Araştırmacılardan Q.Ş İsmailov da spiral deseninin güneş inancını yansıttığını kaydetmiştir (İsmayılsade, 2008: 50). Araştırmacı İ. Avşarov, E.İ. Krupnov ve R.M. Munçayev'in fikrine dayanarak spiral sembolün İran ve Mezopotamya sanatı için çok da yaygın olmadığını, Ön Asya sanatında tasvir edilen spiral 
sembolün zamanın sonsuzluğunu, güneşin, ayın, yıldızların hareketini ve uzun ömürlülüğü sembolize ettiğini kaydeder (Avşarova, 2014: 89). L. Kerimov'un düşüncesine göre; Azerbaycan'ın birçok bölgelerinden bulunmuş halıların üzerindeki spiral semboller "suyu" ifade eder (Керимов, 1983: 129). Afrika ülkelerinin dini ideolojik görüşlerinde, mitolojik Bakuşlarında "dünyaya gelmeyi" sembolize edir (Mirimanov, Çernova, 1964: 75). Saat yönünde olan spiral çizimleri eski Doğu halklarının dini-ideolojik görüşlerinde, mitolojisinde güneşi belirtir. Spiral desenin anlamıyla ilgili bilimsel düşünceler farklı olsa da onları mantıksal yönden birbiriyle birleştiren özelliklerde vardır. Bu özellik sembolünün astrolojik bir anlamı olması ve onun gök cisimlerine olan inancı sembolize etmesidir.

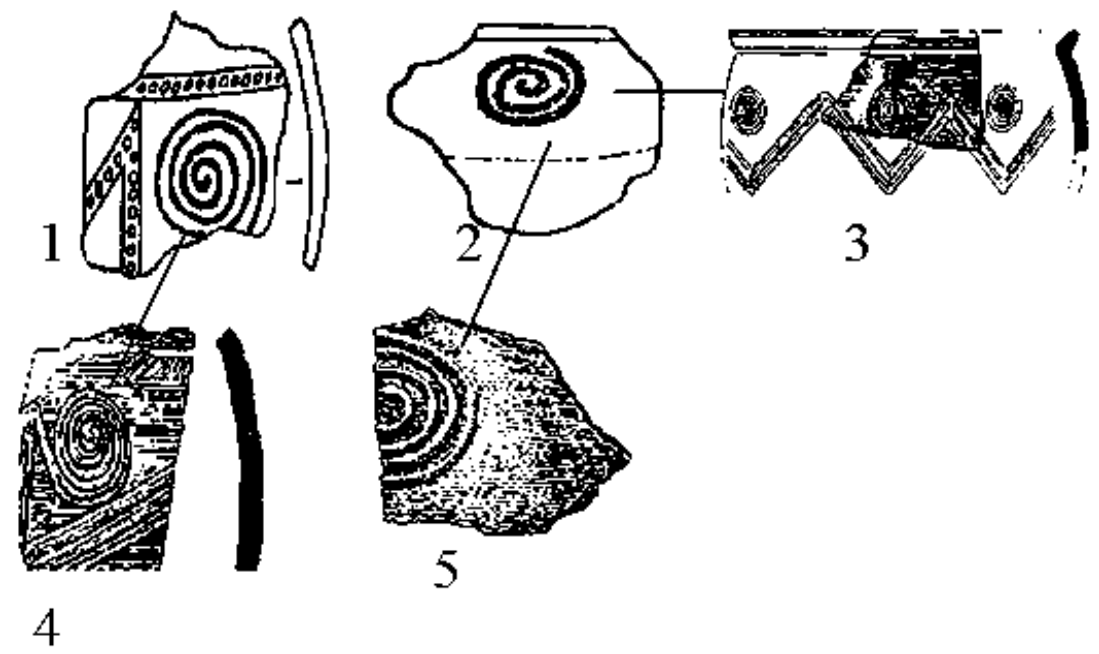

1, 2- II Kültepe (Seidov, 2002); 2, 4- Karaz (Doğu Anadolu-Erzurum); 5-Babaderviş (Kuşnaryeva, Markovin, 1994)

\section{Tablo VI. Spiral Desenli Seramiklerden Örnekler}

Nahçıvan'ın Erken Tunç Çağı seramiklerinin spesifik özelliklerinden biri de bu kapların bir çoğunun ağız kenarının dikdörtgen biçimde dışa çıkması, onların ağızlarının iki taraftan biraz içeri birikmesi ve simetrik olmasıdır. Bazı kapların ağzının kenarı biraz kalın yapılmıştır. II Kültepe'den elde edilmiş bu tür kapların bir grubunun benzerleri Göytepe Erken Tunç Çağı tabakasında da bulunmuştur (Aşurov, 2002: 108). Ağzının kenarı kalın yapılan kil kaplar Doğu Anadolu'da da yaygındır (Koşay 1943:165-169; Koşay-Turfan 1959; Işıklı 2011).

Yapılan inceleme sonucunda Nahçıvan'ın Erken Tunç Çağı sanatı içerisinde seramikçiliğin özel bir yer tuttuğunu görürüz. Bu dönemden başlayarak seramikçiliği ev sanatı dışına çıkması onun gelişimine neden olmuştur. Seramikçiliğin gelişmesi sonucunda yapılan mamullerin hem çeşitleri çoğalmış, hem de kalitesi artmıştır. Seramiklerin yapılmasında, onların süslenmesinde bu sanat alanı ile uğraşan insanların sanatkârlık yeteneğinin yanı sıra düşünce tarzı, dini-ideoloji görüşleri de önemli yer tutmaktadır. Süslemede kullanılan desenler hem sembol, hem de damga gibi kullanılmıştır. Nahçıvan'ın Erken Tunç Çağı seramikleri üzerinde kullanılan desenlerin bir grubu geniş alanda yaygındır. Süslemede yerel desenlerin yanı sıra, diğer kültürlerle benzer özelliklerin bulunması dünyanın farklı bölgelerinde yaşayan insanların dini-ideoloji görüşlerinde benzerliğin olduğunu, her bir desenin derin bir anlamı olduğunu kanıtlamaktadır. 


\section{Kaynakça}

Abibullayev O.A.(1982) Eneolit i bronza na territorii Naxçivanskoy ASSR, Baku, Elm, $314 \mathrm{~s}$. Aliyev Aliyev V.H. (1991) Kultura epoxi sredney bronzı Azerbaydjana, Baku, Elm, 256 s.

Allamuratov A.S. (1977) Karakalpakskaya narodnaya vışka, Nukus, 77 s.

Aşurov S.H. (2002) Naxçıvanın İlk Tunc dövrü keramikası. Bakü, Elm, 158 s.

Avşarova İ. (2014) Azerbaycan tayfalarının ibtidai icma dövrü inanclarında semantik mena daşıyan naxış ve işareler, Azebaycan arxeologiyası ve etnoqrafiyasının aktual problemleri, Bakü, s. 85-98.

Arxeoloqiya Ukraynskoy SSR (1985) Tom Perviy. Kiyev, Dumka, 564 s.

Baxşeliyev V.B. (2004) Nahçıvanın qedim tayfalarının menevi medeniyyeti. Bakü, Elm, $320 \mathrm{~s}$. Braidwood R. J., BraidwoodL. S (1960) Excavations in the Plain of Antioch I: The Earlier Assemblages A-J. Oriental Institute Publications. Chicago.

Burney C. A. (1958) "Eastern Anatolia in the Chalcolithic and Early Bronze Age". Anatolian Studies VIII. 157-209.

Burney C. A. -D. M. Lang (1971) The Peoples of the Hills. Ancient Ararat and Caucasus. London

Ceylan A. (2008) Doğu Anadolu Araştırmalar1-Erzurum, Erzincan, Kars, Iğdır 1998-2008. Erzurum

Çiğdem S. (2000) "Başlangıçtan Eski Tunç Çağı Sonuna Kadar Erzurum Ve Yöresi Geçim Kaynakları”. Atatürk Üniversitesi Sosyal Bilimler Dergisi-26. Erzurum. 2000. 197-210.

Dyson (1968) "The Archaeological Evidence of the Second Millennium B. C. on the Persian Plateau". The Cambridge Ancient History-II. 14-16.

Dyson (1973) "The Archaeological Evidence of the Second Millennium B. C. on the Persian Plateau". The Cambridge Ancient History-2/1. (ed. Edward). Cambridge. 686-715.

Ebülqazi B. (2002) Şecereyi-Terakime: türkmenlerin soy kitabı (red. İ. Ömeroğlu), Bakü, Azerbaycan Milli Ensiklopediyas1 NPB, $146 \mathrm{~s}$

EliyevV . (1976) Babadervişde Son Tunç ve Erken Demir Dövri yaşayış yerleri, AMM, C. VII, Bakü, s. 23-25.

Ferecova M. (2009) Azerbaycan qayaüstü inceseneti. Bakü, Aspoliqraf, 384

İbrahimli B.İ., Qadirzade H.İ., Xelilov T.F., Qadirzade T.Q. (2011) Plovdağ yaşayış yerinde aparılmış arxeoloji qazıntı işleri // Azerbaycanda arxeoloji tedqiqatlar- 2010, Bakü, s. 161-169.

Işıklı M. (2011) Doğu Anadolu Erken Transkafkasya Kültürü. İstanbul: Arkeoloji ve Sanat Yayınları.

İsmailzade Q.S. (2008) Azerbaydjan v sistema rannebronzovoy kulturnoy obşnosti Kavkaz, Baku, Elm, $304 \mathrm{~s}$.

Kâşgarlı Mahmud (2011) Divanü Lügat-it Türk, çeviren: Besim Atalay. Türk Dil Kurumu Yayınları: 1036, Ankara $1972 \mathrm{~s}$

Kely M. Bucellati (1974) The Early Trans-Caucasian Culture Geographical and Chronological Interaction, Chicago

Kely M. Bucellati (1979) "The Fertile Crescent Culture: North Eastern Connections of Syria and Palestine in the Third Millennium B. C.”. Ugarit-Forschungen 11. 413-430

Kerimov L. (1983) Azerbaydjanskiy kover. An. Az. SSR İnstitut Arxitektur1 i İskustva, Qandjlik, t. II., Baku, 243 s.

Koşay H. Z. (1943) “Karaz Sondajı”. III. Türk Tarih Kongresi. Ankara. 165-169

Koşay H. Z. Turfan K. (1959) "Erzurum Karaz Kazısı Raporu". Belleten 23/91. Ankara.

Kuftin B. A. (1943) Urartskij "Kolumbarij" u podosvy Ararata i Kuro-Araksskij Eneolit..." Vestnik Gosudarstvennogo muzeja Gruzii 13. 
Krupnov E.İ. (1964) Drevneyşeya kultura Kavkaza i Kavkazskaya etniçeskaya obşnost. SA, №1. 36-39.

Kuşnareva K.X., Çubinaşvili T.N. (1970) Drevniye kulturı Yujnoqo Kafkaza. Leninqrad, 191s. Kuşnareva K.X., Markovin V.İ. (1994) Epoxi bronzı Kavkaza i Sredney Azii. Ranya i Srednya Bronzı Kafkaza (Oçerednoy tom mnoqotomnoqo fundamentalnoqo izdaniya po arxeoloqii), Moskova, Nauka, 384 s.

Müseyibli N.E. (2004) Gemikaya, Bakü, Çaşoğlu, 320 s.

Mirimanov V.B., Çernova Q.A. (1964) İskustva Afrika, Moskova, Nauka, 84 s.

Öztürk. N. (2004) "Anadolu'nun Karaz Seramiğine Ait Eski İle Yeni Görüşleri Ve Yerleşim Yerleri”. Atatürk Üniversitesi Fen-Edebiyat Fakültesi Sosyal Bilimler Dergisi Cilt-4. Say1-32. Erzurum. 81-93

Pehlivan M. (1990) “Karaz Kültürü ve Hurriler”. Yüzüncü Y1l Üniversitesi Fen-Edebiyat Fakültesi Sosyal Bilimler Dergisi 1-1. Van. 168-176.

Qurbanov A. (2003) Damğalar, remzler, menimsemeler. Bakü, Azerbaycan Respublikasının Prezidenti Yaninda Strateji Araştırmalar Merkezi, 327 s.

Piotrovskii B. B. (1964) "The Aeneolithic Culture of Transcaucasia in the Third Millennium B. C.” VI. International Congress of Prehistoric and Protohistoric Sciences. Moscow. 360-366

Seidov A.Q. (1993) Pamyatniki kura.arakskoy kulturı Naxçevani. Baku, 184 s.

Seidov A.Q. (2002) Rannebronzovaya kultura Naxçıvana. Voranej. VQTU, 193.

Seyidov A.Q. (2003) Nahçıvan e.a. VII-II minilliklerde. Bakü, Elm, 339 s.

Sagona. A. -Sagona C. (2003) "The upper Levels at Sos Höyük, Erzurum: A Reinterpretation of the 1987 Campaign", Anatolia Antiqua XI. 101-10.

Yengi M. R., Bextiyar T. (2013) Kür-Araz medəniyyəti və türk damğaları: Damğadan yazıya keçid, Bakü, Elm, 83 s.

http://azerbaijani-studies.blogspot.com/2013/01/yazmzn-baslangc-gmiqayadak-turk_17.html https://onturk.org/tag/saymalitas

https://uqusturk.wordpress.com

https://uqusturk.wordpress.com/2011/08 / 22 / orta-asyadan-anadoluya-anadolu-avrupaya-ozdamgasi

http://onedio.com/haber/nazilerin-kirlettigi-bir-mutluluk-sembolu-svastika--417203 